Original Research Article

\title{
Analysis of adverse drug reactions in a tertiary care emergency medicine department: prevalence, preventability and reporting
}

\author{
Shreya R. Patel ${ }^{1}$, Sapna D. Gupta ${ }^{2 *}$, Kamlesh P. Patel ${ }^{1}$, Supriya D. Malhotra ${ }^{1}$, Pankaj R. Patel ${ }^{3}$
}

${ }^{1}$ Department of Pharmacology, ${ }^{2}$ Department of Emergency Medicine,

${ }^{3}$ Dean, Department of Orthopaedics, Smt. NHLMMC, VSGH, Ahmedabad, Gujarat, India

Received: 05 July 2018

Accepted: 30 July 2018

*Correspondence to:

Dr. Sapna D. Gupta,

Email: sapna_gupta76@

gmail.com

Copyright: (C) the author(s), publisher and licensee Medip Academy. This is an openaccess article distributed under the terms of the Creative Commons Attribution NonCommercial License, which permits unrestricted noncommercial use, distribution, and reproduction in any medium, provided the original work is properly cited.

\begin{abstract}
Background: Adverse drug reactions (ADRs) are negative consequences of drug therapy. ADR results in diminished quality of life, increased physician visits, hospitalizations, and even death. Hence a study was planned to detect and analyze ADR encountered in emergency medicine department.

Methods: Data was collected over a period of 1 year after taking approval from IRB (Institutional Review Board) and written informed consent from patients. ADRs presenting as a cause of hospital admission or developed during hospitalization were analyzed.

Results: A total of 229 ADRs were analyzed. Majority of ADRs were found in the age group of 40-60 Years. The M: F Ratio was 1.10:1. According to Wills and Brown Classification, majority of the ADRs belonged to Type A. According to Hartwig and Siegel classification of severity of ADRs, $18.78 \%$ of the ADRs were severe in nature. According to Schumock and Thornton preventability score, majority $(64.19 \%)$ of the ADRs were not preventable, whereas $17.03 \%$ were definitely preventable. $120(52.40 \%)$ of the ADRs were serious in nature Antiinfective were the most common drug class $(30.13 \%)$ followed by CVS $(24.03 \%)$ group of drugs. About (57.64\%) ADRs fall in the category of probable/likely. Regarding their Outcome, $44.10 \%$ of the ADRs were recovered and $43.23 \%$ were recovering.

Conclusions: Anti-infective were the most reported drug class to cause ADRs in a tertiary care emergency medicine department. Causality assessment according to WHO-UMC and Naranjo's causality assessment criteria reported to be Probable. Whereas modified Schumock and Thornton scale preventability scale showed that majority were not preventable.
\end{abstract}

Keywords: Adverse drug reactions, Causality, Emergency Medicine Department

\section{INTRODUCTION}

Adverse drug reaction (ADR) is defined by the World Health Organization (WHO) as "any noxious, unintended or undesired effect of a drug that occurs at doses used in humans for prophylaxis, diagnosis, therapy or modification of physiological functions". ${ }^{1}$ Drug-related problems (DRP), including adverse drug reactions (ADRs), constitute a significant health- and quality problem particularly affecting the elderly. ${ }^{2}$ ADRs are the fourth leading cause of death. ${ }^{3}$
In 2010, Central Drugs Standard Control Organization (CDSCO) under the aegis of Govt., of India, Ministry of Health and Family welfare and Pharmacovigilance Programme of India (PvPI) has established adverse drug monitoring centers in various tertiary care hospitals all over India with the objective to improve the reporting rate of ADRs in India. ${ }^{4}$ Adverse drug reactions (ADRs) are negative consequences of drug therapy. ${ }^{5}$ The numerous medications, multiple chronic medical problems, and frequent acute illnesses experienced by the patients put them at increased risk for ADRs and makes detection more 
difficult. $^{5}$ ADR results in diminished quality of life, increased physician visits, hospitalizations, and even death. Hence a study was planned to detect and analyze ADR encountered in emergency medicine department. Pharmacovigilance (PV) is defined as the science and activities relating to the detection, assessment, understanding, and prevention of adverse effects or any other drug-related problems. ${ }^{6}$ In Emergency medicine department, very critical and hemodynamically unstable patients are treated. They require multiple drugs at a time and also drugs with narrow therapeutic index. Hence, an attempt has been made in this study to analyze the clinical spectrum and assess seriousness, outcome, causality, severity, and preventability of the ADRs in the emergency medicine department's patients.

\section{Objectives}

- To detect and analyze adverse drug reactions encountered in tertiary care emergency medicine department

- To identify diseases and drugs most frequently encountered in emergency department and responsible for ADRs and subsequent hospital admissions.

\section{METHODS}

After the approval of study protocol by Institutional Review Board and written informed consents were taken from patients. Data was collected over a period of 12 months ADRs reported in emergency medicine department or occurring in hospitalized patients of our hospital during the period from June 2016 to June 2017 were collected. Relevant data were collected in case record form. Demographic data of the patient were recorded. Relevant details of each ADRs were collected in suspected ADR reporting form (PVPI-NCC-IPC). ${ }^{7}$ Each report was sent to the National coordinating center through Vigiflow. The data were analyzed according to the strength of association, causal relationship between suspected drug and ADRs, number of ADRs, time relationship, and involved body system as per system organ classification. ADRs were also categorized based on age of the patients and gender. Types of ADRs were classified based on Wills and Brown classification. ${ }^{8}$ In which Type A (augmented), Type B (bugs), type C (chemicals), type D (delivery), type $\mathrm{E}$ (exit), type $\mathrm{F}$ (familial), type $\mathrm{G}$ (genotoxicity), type $\mathrm{H}$ (hypersensitivity), type $\mathrm{U}$ (unclassified) reactions. The severities of the ADRs were analyzed in to mild, moderate and severe categories according to Modified Hartwig and Seigel criteria. ${ }^{9}$ The seriousness of ADRs were graded as per the suspected ADR reporting form criteria (IPC-PVPI). The categories were death, life-threatening, hospitalization/prolongation of hospitalization, disability, congenital anomaly and others. Natures of preventability of ADRs were assessed by modified Schumock and Thornton preventability scale. ${ }^{10}$ Causality assessment was carried out based on the WHO UMC criteria. ${ }^{11}$ The outcome of the reaction was analyzed according to the suspected ADR reporting form.

\section{RESULTS}

Out of 30295 number of hospital admission total 229 ADRs were collected and analyzed for the type, severity, seriousness, causality and preventability of the ADRs. Majority of the ADRs were developed within 1 week of admission.

\section{Demographic data of patients with suspect ADR}

In this study out of the 229 patients maximum numbers of patients were from 40-60 years of age group. Female preponderance was more, $118(51.52 \%)$ were females and $111(48.47 \%)$ were males. The male female ratio was 1.10:1 (Table 1).

Table 1: Age group according distribution of ADRs.

\begin{tabular}{|lll|}
\hline AGE (years) & No. of ADRs & Percentage \\
\hline $0-20$ & 25 & $10.92 \%$ \\
\hline $20-40$ & 59 & $25.77 \%$ \\
\hline $40-60$ & 80 & $34.93 \%$ \\
\hline$>60$ & 65 & $28.38 \%$ \\
\hline Total & 229 & $100 \%$ \\
\hline
\end{tabular}

\section{Type and severity of suspect ADRs}

According to Wills and Brown classification, majority of the ADRs belonged to Type A (53.71\%) followed by Type B $(13.54 \%)$, Type C $(2.18 \%)$, Type D $(0.44 \%)$, Type E (6.55\%), Type G $(1.31 \%)$, Type H $(10.92 \%)$, Type U (11.35\%) (Figure 1).

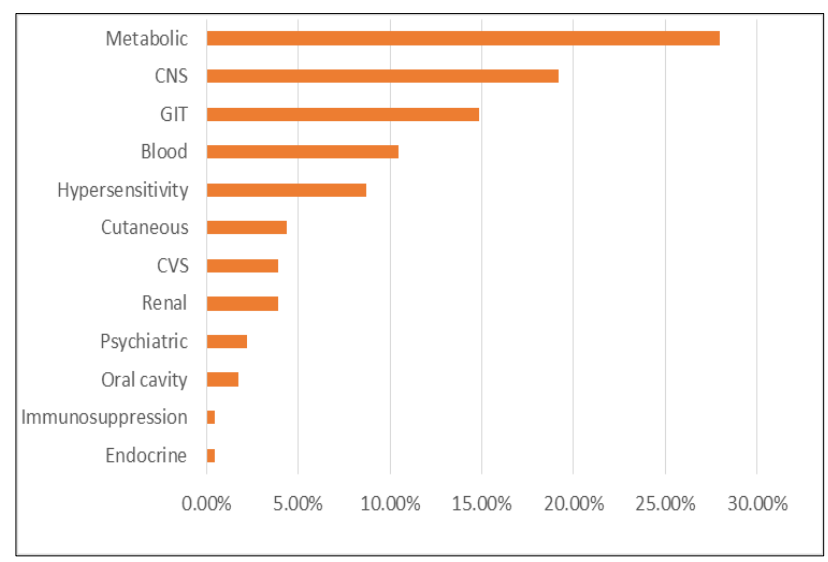

Figure 1: Systems involved in the ADRs.

\section{Seriousness of reactions}

There were $113(49.34 \%)$ serious reactions and 116 $(50.65 \%)$ non-serious reactions were reported. Among serious ADRs death in 4 patients, hospitalization in 60 patients, prolongation of hospitalization in 26 patients, life 
threatening consequences in 15 patients, intervention needed in 7 patients and other seriousness in 1 patient were noted.

\section{Causality of drugs implicated in suspect ADRs}

According to WHO-UMC causality assessment score, $132(57.64 \%)$ ADRs fall in to category of Probable/Likely while others $91(39.74 \%)$ were possible and 6(2.62\%) were certain/likely.

\section{Preventability of the reactions}

According to modified Schumock and Thornton preventability score $147(64.19 \%)$ of the ADRs were not preventable whereas 43 (18.78\%) ADRs probably preventable and $39(17.03 \%)$ were definitely preventable (Table 2).

Table 2: Preventability of ADRs according to modified Schumock and Thornton scale.

\begin{tabular}{|ll|}
\hline $\begin{array}{l}\text { Definitely } \\
\text { Preventable } \\
\mathbf{1 7 . 0 3 \% ( 3 9 )}\end{array}$ & $\begin{array}{l}\text { Insulin- Hypokalemia } \\
\text { Penicillin- Anaphylactic shock } \\
\text { Phenytoin- Gum Hyperplasia } \\
\text { and Ataxia } \\
\text { Contrast Media-Nephropathy } \\
\text { Toxic }\end{array}$ \\
\hline $\begin{array}{l}\text { Probably } \\
\text { Preventable } \\
18.78 \%(43)\end{array}$ & $\begin{array}{l}\text { ATT- Hepatitis, Jaundice } \\
\text { Phenytoin- Withdrawal Seizures }\end{array}$ \\
\hline $\begin{array}{l}\text { Not Preventable } \\
64.19 \%(147)\end{array}$ & $\begin{array}{l}\text { Cefaperazone- Diarrhea, SGPT } \\
\text { increased, Rash } \\
\text { Ceftriaxone- Rash, Anaphylactic } \\
\text { shock }\end{array}$ \\
\hline
\end{tabular}

\section{Severity of the reactions}

According to Hartwig and Siegel classification of severity of ADRs majority of the ADRs 118 (51.53\%) were mild in nature whereas other $68(29.69 \%)$ were moderate and 43 $(18.78 \%)$ severe in nature (Table 3 ).

Table 3: Severity of ADRs according to modified Hartwig and Siegel scale.

\begin{tabular}{|lll|}
\hline Severity & No. Of ADRs & Percentage \\
\hline Mild & 118 & $51.53 \%$ \\
\hline Moderate & 68 & $29.69 \%$ \\
\hline Severe & 43 & $18.78 \%$ \\
\hline
\end{tabular}

\section{Suspected drug classification}

Majority of the ADRs belonged to the Anti-infective class of drugs $69(30.13 \%)$, followed by cardiovascular drugs 55 (24.03\%), central nervous drugs 42 (18.34\%) and Antidiabetics $35(14.85 \%)$, Steroids and antiinflammatory 17 (7.42\%) and Miscellaneous 12 (5.24\%) group of drugs (Figure 2).

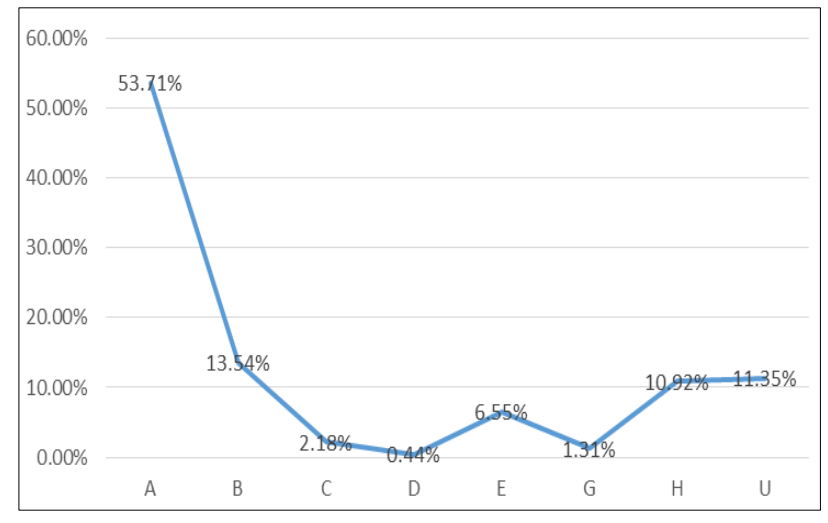

Figure 2: Types of ADRs according to wills and Brown classification.

\section{Outcome of ADRs}

Out of 229 ADRs, $101(44.10 \%)$ rest 3\% ADRs did not recovered completely and other $99(43.23 \%)$ were in the phase of recovering, $24(10.49 \%)$ ADRs were unknown and $5(2.18 \%)$ ADRs did not recovered.

\section{SOC of ADRs}

Majority of the ADRs 64 (27.95\%) belonged to metabolic system, followed by 44 (19.21\%) CNS, 34 (14.85\%) GIT, $24(10.48 \%)$ Blood, 20(8.74\%) Hypersensitivity, 10 $(4.37 \%)$ cutaneous, 09(3.93\%) CVS,09 (3.93\%) renal, 5 $(2.18 \%)$ psychiatric, $4(1.75 \%)$ oral cavity, $4(1.75 \%)$ respiratory, $1(0.44 \%)$ immunosuppressant, 1 (0.44\%) endocrine system (Figure 3).

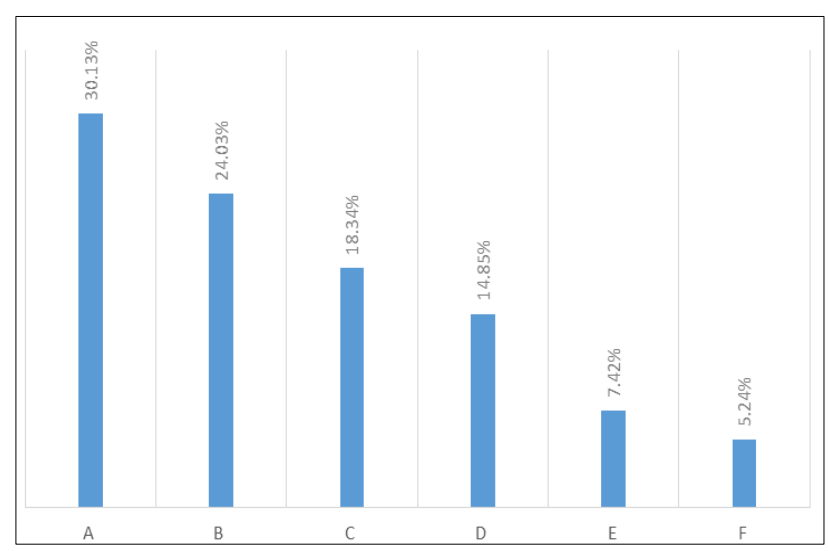

Figure 3: Suspected drug class of ADRs.

\section{DISCUSSION}

The aim of our study was to determine the prevalence and preventability and seriousness of ADRs in an emergency ward setting in a tertiary hospital. And critical fluctuations of vital data make it mandatory for minute to minute pharmacological intervention many a times. Coexisting drug therapy and electrolyte disturbances also make these patients more susceptible to adverse effects. Now a days hospital admission due to ADRs are major concern and to 
detect, analyze those patients is difficult for clinician. According to the World Health Organization, costs of ADRs, including hospitalizations, surgery and lost productivity, exceed the cost of medicines in some countries. ${ }^{12}$ But by present study one can know how much the prevalence is and how many ADRs can be prevented.

In this study also we found similar results, majority of the ADRs were from Type A category. et al. In one review they reported that more than $80 \%$ of ADRS causing admission or occurring in the hospital are Type $\mathrm{A}$ in nature and thus predictable from the known pharmacology of the drug and therefore potentially avoidable. Among serious ADRs majority of the patients lead to hospitalization. ${ }^{13}$

This study showed slight female preponderance. In the general population, female gender has been identified as an independent risk factor for ADR-related hospital admissions (Figure 3). ${ }^{14}$

In this study, most of the serious ADRs were the ones which lead to hospitalization. Although ADRs which were non-serious were more in number. In India, according to one meta-analysis, the occurrence of ADRs in hospitalized patients is around 6-7\%.and admission in hospital due to adverse drug reaction is around $2-3 \% .{ }^{15} \mathrm{We}$ observed death due to anaphylactic reactions in 2 patients, nephropathy following Contrast media administration in 1 patient and intracranial haemorrhage due to Warfarin in 1 patient. All these four cases ADRs were severe in nature. These deaths due to ADRs could be avoided to some extent if drug history is elicited from the patients, test dose of such allergic drugs given prior to full dose, withdrawing of certain drugs Metformin, Cyclosporine, Gentamicin, Furosemide before administration of Contrast media, careful monitoring of INR and possible drug-drug interaction with Warfarin therapy. ${ }^{16}$ Prolongation of hospitalization was because of electrolyte imbalance such as hypokalaemia, hypernatremia, hypoglycaemia in majority of the patients. Survey by Bukley MS et al, noted that electrolyte imbalances are common in critically ill patients. Multiple disease states and medicines contribute to such electrolytes imbalances, altered hormonal responses affecting homeostasis, directly impact organ function responsible for maintaining electrolyte balance. ${ }^{17}$

In this study $17.03 \%$ were preventable. Majority of the ADRs were not preventable (64.19\%) because in this study ADRs from anti-infective drug class were maximum, and to prevent opportunistic infections they were prescribed in almost all the hospitalized patients. In the as mentioned study, $10.9 \%$ is estimated to experience an ADR after admission to emergency ward, during their hospital stay. ${ }^{13}$ In this study majority of the ADRs developed within one week of hospital stay. Possible reason for that were pharmacodynamics, pharmacokinetics alterations, drugdrug interactions, poly pharmacy and comorbidities. And also, sepsis is most commonly occurring diagnosis either as presentation or during hospital stay. Study by Lazarou et al, suggested that $28.9 \%$ of the ADR-related hospitalizations were considered preventable. ${ }^{13}$

In contrast, our study found that non-preventable ADRs were more, may be because of anti-infective class of drugs being most prescribed. Preventable ADRs belonged to anti diabetics group of drugs. This could be because of improper advice related to their usage, lack of knowledge of the patients, necessary laboratory tests not performed or preventative measures not prescribed when administering drug to patients. Asawari L Rau et al, on preventability showed about $55 \%$ of ADRs were preventable, while $45 \%$ were non-preventable. Among the preventable ADRs $34 \%$ were definitely preventable because of an inappropriate selection of drug for patient's condition and due to established available treatment for the ADRs. They also reported same causes for preventable ADRs. ${ }^{18}$ James BC and McDonnell et. al study showing $60.5 \%$ and $62.3 \%$ of the ADRs as preventable respectively. ${ }^{19}$

Hanlon and colleagues documented all and preventable ADRs in 808 frail older patients recently discharged from hospital or emergency room and followed for up to 1 year. Overall, $33 \%$ of patients had one or more ADRs for a rate of 1.92 per 1000 person-days of follow-up and the rate for preventable ADRs was 0.71 per 1000 person-days of follow-up. ${ }^{20}$

In this study, regarding ADRs outcome and severity majority of the ADRs were recovered and were of mild severity in nature. This was because of action taken immediately, watchfulness of the clinicians, awareness regarding reporting of ADRs. ADRs such as electrolyte imbalance, rashes were noted as mild and recovering or recovered.

The common causality association with suspected drug was 'probable' and 'possible' in majority of cases. Similar observations have been reported by Pauldurai et al, and Amin et al. ${ }^{21}$ This study and Type A ADRs were more in number similar to results of study by $\mathrm{M}$ shamna et al. ${ }^{22}$

\section{CONCLUSION}

This study data shows, majority of the ADRs belonged to Type A. Non-serious ADRs were more common than serious ones. The most common body system involved being Metabolic and CNS. Anti-infectives were the most reported drug class to cause ADRs. Also, most of these ADRs belonged to recovered and recovering phase. Causality Assessment in majority of ADRs was Probable/Likely. Hence our data is useful regarding the severity, outcome, preventability, which will be helpful for future study as well as for spreading awareness among the physicians and layman. However, the limiting factors in this study are Under-reporting; sometimes the drugs causing adverse effects have to be continued even though patient has reacted to it, like higher antibiotics and antiepileptics. Thus, requiring time to time analysis of risk benefit ratio of drugs and patient's condition. 
According to our results, majority of the ADRs which occurred by Anti-diabetics drugs are definitely Preventable and Recoverable. Hence physician should focus on counselling related to taking Antidiabetics and to recognize early signs of Hypoglycaemia in this patient group. ADRs because of Antiepileptic drugs such as Phenytoin, Levetirecetam, Valproate are Probably preventable. Majority of ADRs occurred by antibiotics and they are not preventable. Hence, one should be watchful for use of antibiotics.

\section{ACKNOWLEDGEMENTS}

Authors would like to thank Department of Emergency Medicine for their constant help and support during the study. They would also like to thank Dr. S. T. Malhan, superintendent of this institute for his constant guidance and encouragement.

\section{Funding: No funding sources}

Conflict of interest: None declared

Ethical approval: The study was approved by the Institutional Ethics Committee

\section{REFERENCES}

1. World Health Organization. International drug monitoring: The role of the hospital. In: Technical Report Series No. 425. Geneva, Switzerland: World Health Organization; 1966:1-24.

2. Rydberg DM, Holm L, Engqvist I, Fryckstedt J, Lindh JD, Stiller CO, et al. Adverse drug reactions in a tertiary care emergency medicine ward-prevalence, preventability and reporting. PloS one. 2016 Sep 13;11(9):e0162948.

3. Lobo MG, Pinheiro SM, Castro JG, Momenté VG, Pranchevicius MC. Adverse drug reaction monitoring: Support for pharmacovigilance at a tertiary care hospital in Northern Brazil. BMC Pharmacol Toxicol. 2013;8:14:5

4. Lihite RJ, Lahkar M. A study on cutaneous adverse drug reactions in ADR monitoring centre of tertiary care hospital, Guwahati. J Appl Pharm Sci. 2013;3:7881.

5. Mohammed G, Sunil T, Bandari K, Shravan D. A Prospective observational study on monitoring, evaluating and reporting of ADRs in A tertiary care hospital. WJPPS. 2015;5(2):736-52.

6. Pharmacovigilance, WHO 2014. Available at: http://www.who.int/ medicines/areas/quality_safety/safety_efficacy/pharm vigi/en/ [Last accessed on 2018 May 19].

7. Adverse drug reaction reporting form. Central Drugs Standard Control Organisation. Available at: www.cdsco.nic.in/forms/Default.aspx.

8. Angeline. From Evaluation to prevention of Adverse Drug Reaction. Int J Pharm. 2015;5(4):1170-7.
9. Hartwig SC, Siegel J, Schneider PJ. Preventability and severity assessment in reporting adverse drug reactions. Am J Hosp Pharm. 1992;49:2229-32.

10. Schumock GT, Thornton JP. Focusing on the preventability of adverse drug reactions. Hosp Pharm. 1992;27:538.

11. Hartwig SC, Siegel J, Schneider PJ. Preventability and severity assessment in reporting adverse drug reactions. Am J Hosp Pharm. 1992;49:2229-32.

12. Schumock GT, Thornton JP. Focusing on the preventability of adverse drug reactions. Hosp Pharm. 1992;27:538.

13. Lazarou J, Pomeranz BH, Corey PN. Incidence of adverse drug reactions in hospitalized patients: a metaanalysis of prospective studies. JAMA. 1998 Apr 15;279(15):1200-5.

14. Pirmohamed M, James S, Meakin S, Green C, Scott AK, Walley TJ, et al. Adverse drug reactions as cause of admission to hospital: prospective analysis of 18 820 patients. BMJ. 2004 Jul 1;329(7456):15-9.

15. Patel TK, Patel PB. Incidence of Adverse Drug Reactions in Indian Hospitals: A Systematic Review of Prospective Studies. Curr Drug Saf. 2016;11(2):128-36.

16. Morcos SK. Interactions with Other Drugs and Clinical Tests. In: Thomsen HS, Webb JAW (Eds). Contrast Media. $2^{\text {nd }}$ Ed. Springer-Verlag Berlin Heidelberg: 2009:107-114.

17. Buckley MS, Leblanc JM, Cawley MJ. Electrolyte disturbances associated with commonly prescribed medications in the intensive care unit. Crit Care Med. 2010 Jun;38(6):S253-64.

18. Raut A, Patel P, Patel C, Pawar A. Preventability, predictability and seriousness of adverse drug reactions amongst medicine inpatients in a teaching hospital: a prospective observational study. Int J Phar Chem Scienc. 2012;1(3):1293-99.

19. James BC. Every defect a treasure: learning from adverse events in hospitals. Med J Aust. 1997; 166:484-7.17.

20. Hanlon JT, Pieper CF, Hajjar ER, Sloane RJ, Lindblad CI, Ruby CM, et al. Incidence and predictors of all and preventable adverse drug reactions in frail elderly persons after hospital stay. The Journals of Gerontology Series A: Biological Sciences and Medical Sciences. 2006 May 1;61(5):511-5.

21. Amin S, Shah S, Desai M, Shah A, Maheriya KM. An analysis of adverse drug reactions in extremes of age group at tertiary care teaching hospital. Perspect Clin Res. 2018;9:70-5.

22. Shamna M, Dilip C, Ajmal M, Mohan PL, Shinu C, Jafer CP, et al. A prospective study on Adverse Drug Reactions of antibiotics in a tertiary care hospital. Saudi Phar J. 2014 Sep 1;22(4):303-8.

Cite this article as: Patel SR, Gupta SD, Patel KP, Malhotra SD, Patel PR. Analysis of adverse drug reactions in a tertiary care emergency medicine department: prevalence, preventability and reporting. Int J Basic Clin Pharmacol 2018;7:1787-91. 